\title{
Multicenter early experience with extended aortic repair in acute aortic dissection: Is simultaneous descending stent grafting justified?
}

\author{
Konstantinos Tsagakis, MD, ${ }^{\mathrm{a}}$ Davide Pacini, MD,${ }^{\mathrm{b}}$ Roberto Di Bartolomeo, $\mathrm{PhD},{ }^{\mathrm{b}}$ Michael Gorlitzer, $\mathrm{MD},{ }^{\mathrm{c}}$ \\ Gabriel Weiss, MD, ${ }^{\mathrm{c}}$ Martin Grabenwoger, $\mathrm{PhD},{ }^{\mathrm{c}}$ Carlos A. Mestres, PhD, ${ }^{\mathrm{d}}$ Jaroslav Benedik, MD, ${ }^{\mathrm{a}}$ \\ Stepan Cerny, $\mathrm{PhD},{ }^{\mathrm{e}}$ and Heinz Jakob, $\mathrm{PhD}^{\mathrm{a}}$
}

\begin{abstract}
Objective: In acute type A aortic dissection, the extension of repair to downstream aorta has been controversially discussed. We present the early results of a multicenter study using a hybrid stent graft prosthesis.

Methods: Between January 2005 and January 2010, the data from 191 patients after combined proximal aortic replacement and antegrade stent grafting were collected in the database of the International E-vita open Registry. Of the 191 patients, 68 underwent surgery for acute aortic dissection and were included in the present study. Hypothermic circulatory arrest and selective cerebral perfusion were routinely used. Computed aortic imaging was performed for false lumen evaluation during follow-up.
\end{abstract}

Results: The in-hospital mortality rate was $13 \%$ (9/68). Along the stent graft, the rate of immediate complete false lumen thrombosis was $86 \%$ (51/59) and increased during follow-up ( $23 \pm 17$ months) to 94\% (46/49). Distally, complete or partial false lumen thrombosis was initially observed in $61 \%(36 / 59)$ and in $82 \%(40 / 49)$ after follow-up. The 1- and 3-year actuarial survival rate was $82 \%$ and $74 \%$, respectively.

Conclusions: Extended thoracic aortic repair of acute aortic dissection with a hybrid stent graft is feasible at acceptable early mortality and promotes false lumen thrombosis around the stent graft and below. (J Thorac Cardiovasc Surg 2010;140:S116-20)

In thoracic aortic surgery, a combination of a vascular prosthesis with a stent graft enables extension of the repair into the descending aorta using a median sternotomy. ${ }^{1-4}$ Although the feasibility of this approach has been proved during the past 2 decades, in acute type A dissection extension of repair downstream from the arch is a matter of controversy. ${ }^{5}$ The use of a stent graft has been regarded as an additional surgical step in an already acute and critical situation increasing the risk of the procedure. Therefore, a multicenter study was initiated to evaluate extended aortic repair into the downstream aorta using a hybrid stent graft in acute aortic dissection. The present study reports the early results of this approach, including the behavior of the false lumen during the follow-up.

From the Department of Thoracic and Cardiovascular Surgery, ${ }^{a}$ West-German Heart Center Essen, University Hospital Essen, Essen, Germany; the Department of Cardiac Surgery, ${ }^{\text {b }}$ S. Orsola-Malpighi Hospital, University of Bologna, Bologna, Italy; the Department of Cardiovascular Surgery, ${ }^{c}$ Hospital Hietzing, Vienna, Austria; the Department of Cardiovascular Surgery, ${ }^{\mathrm{d}}$ Hospital Clínico, University of Barcelona, Barcelona, Spain; and the Department of Cardiac Surgery, ${ }^{\mathrm{e}} \mathrm{Na}$ Homolce Hospital, Prague, Czech Republic.

Disclosures: Heinz Jacob, Konstantinos Tsagakis, Davide Pacini, Roberto Di Bartolomeo, Michael Gorlitzer, Gabriel Weiss, Martin Grabenwoger, Carlos A. Mestres, Jaroslav Benedik, and Stepan Cerny have nothing to disclose with regard to commercial support.

Received for publication April 29, 2010; revisions received July 6, 2010; accepted for publication July 30, 2010.

Address for reprints: Konstantinos Tsagakis, MD, Department of Thoracic and Cardiovascular Surgery, West-GermanHeart Center Essen, University Hospital Essen, Hufelandstrasse 55, Essen 45122, Germany (E-mail: konstantinos.tsagakis@ uk-essen.de).

$0022-5223 / \$ 36.00$

Copyright $(\odot 2010$ by The American Association for Thoracic Surgery doi:10.1016/j.jtcvs.2010.07.066

\section{MATERIALS AND METHODS}

For patient collection and data analysis, the database of the International E-vita Open Registry was used. ${ }^{6}$ The data selection was approved by the Institutional Review Board of University of Essen, Essen, Germany. Between January 2005 and January 2010, the data from 191 patients with thoracic aortic disease were delivered to the Registry. In all cases, the E-vita open stent graft (Jotec GmbH, Hechingen, Germany) hybrid prosthesis ${ }^{7}$ was used, and the patients underwent surgery in 5 European centers (Barcelona, Spain; Bologna, Italy; Essen, Germany; Hietzing, Vienna, Austria; and Prague, Czech Republic). Of these patients, 68 underwent surgery for acute aortic dissection and were included in the present study. The decision to perform more aggressive therapy by a stent graft was made at the surgeon's discretion, and no criteria were established among the centers for patient selection. The mean age of the patients was $58 \pm 12$ years (range, 32-77 years), and the false lumen involved the proximal aorta and extended into the descending aorta in all cases. Acute was defined as dissection that underwent surgical repair within 14 days after the onset of symptoms. The patients requiring inotropics, with cardiac tamponade, cardiac malperfusion, and acute renal failure were classified as severely, hemodynamically compromised.

In 50 patients $(74 \%)$, the primary diagnosis was made at an external clinic and in $18(26 \%)$ at the treating institution. The extension of dissection was evaluated by computed tomography $(64 / 68,94 \%)$ and/or angiography $(27 / 68,40 \%)$. The choice of stent graft size was made according to the preoperative computed tomography measurements of the true lumen at the descending aorta level and/or according to intraoperative sizing of the true lumen distal to the left subclavian artery using flexible seizers. No guidelines regarding oversizing were agreed on among the surgeons. In addition, no standardized protocol was used for stent graft insertion (over-the-wire technique or not), for the level of the distal anastomosis, for reimplantation of the supra-aortic vessels (as an island or separate), or for the use of the integrated polyester prosthesis for arch replacement. For cerebral protection, selective bilateral antegrade cerebral perfusion was favored and performed in all patients.

During follow-up, the patients were examined by physicians, and the behavior of the false lumen was evaluated by computed tomography or 
magnetic resonance imaging. In these cases, a follow-up was defined as complete. The follow-up examinations were performed postoperatively, after 6 and 12 months, and annually thereafter.

\section{E-Vita Open Stent Graft}

The E-vita open stent graft consists of a 15-cm-long, self-expandable, nitinol-covered stent graft with an integrated nonstented vascular prosthesis ( $7 \mathrm{~cm}$ unstretched) on the top. The stent graft was implanted antegradely into the descending aorta through the opened aortic arch using a flexible delivery system in an over-the-wire technique. After deployment, the stent graft was fixed continuously with the aortic stump by polypropylene suture, and the vascular prosthesis was pulled back to the arch position for continuous arch replacement and re-insertion of the supra-aortic vessels.

\section{Statistical Analysis}

The Statistical Package for Social Sciences, version 16.0, software package (SPSS Inc, Chicago, Ill) was used for statistical analysis. Categorical and continuous variables are expressed as frequencies and mean \pm standard deviation, respectively. The 2 -sided Fisher exact test in categorical and the 2-tailed unpaired $t$ test in continuous variables were used for $P$ value evaluation. The Kaplan-Meier actuarial method was performed for the evaluation of survival and the freedom of secondary interventions within the total patient cohort.

\section{RESULTS}

\section{Status at Admission}

Thirteen patients $(19 \%)$ were intubated before admission to the surgical institution, and 58 patients $(85 \%)$ underwent surgery within 24 hours after the onset of symptoms. A severe hemodynamic compromised status was documented in 33 cases $(49 \%)$, including 21 patients $(31 \%)$ requiring inotropic support, $13(19 \%)$ with tamponade, $10(15 \%)$ with cardiac malperfusion, and $18(27 \%)$ with acute renal failure and anuria. Malperfusion syndromes occurred in 38 patients $(56 \%)$ (Table 1). The primary entry was identified in the ascending aorta or in the arch in 61 patients $(90 \%)$ and in the descending aorta $7(10 \%)$. The presence of a re-entry along the descending aorta was verified in 36 patients $(53 \%)$. A collapse of the true lumen was documented in 35 patients $(52 \%)$, and the false lumen extended along the descending into the abdominal aorta in $63(93 \%)$.

\section{Intraoperative Data}

Arch replacement was performed under selective cerebral perfusion (mean, $68 \pm 20$ minutes) in all cases. The mean interval of hypothermic circulatory arrest was $8 \pm 6$ minutes and the mean interval of visceral ischemia was $71 \pm 22 \mathrm{~min}-$ utes. In most cases, a $24-\mathrm{mm}(32 \%)$ or $28-\mathrm{mm}(34 \%)$ stent graft (mean, $28 \pm 4 \mathrm{~mm}$ ) was used, and an oversizing greater than $10 \%$ was performed in 12 cases $(18 \%)$ (Table 2 ). Stent graft placement was achieved using the over-the-wire technique in 37 patients $(54 \%)$ and without the technique in $31(46 \%)$. One complicated stent graft insertion was reported by placement of the stent graft into a previously implanted uncovered stent at the distal descending level, but stent graft deployment was successful in all cases. For arch replacement, the integrated vascular prosthesis was
TABLE 1. Patient characteristics $(n=68)$

\begin{tabular}{lc}
\hline \multicolumn{1}{c}{ Characteristic } & Value \\
\hline Age $(\mathrm{y})$ & $58 \pm 12$ \\
Age $\geq 70$ y & $12(18)$ \\
Male & $52(77)$ \\
Marfan syndrome & $5(7)$ \\
Emergency & $58(85)$ \\
Intubated before admission & $13(19)$ \\
Inotropic support & $21(31)$ \\
Cardiac tamponade & $13(19)$ \\
Aortic valve regurgitation $\geq 2$ & $40(59)$ \\
Malperfusion & \\
Cardiac & $10(15)$ \\
Cerebral & $15(22)$ \\
Visceral & $8(12)$ \\
Peripheral & $10(15)$ \\
Coronary artery disease & $9(13)$ \\
After stroke & $4(6)$ \\
After cardiovascular surgery & $4(6)$ \\
\hline Data in parentheses are percentages.
\end{tabular}

used in $36(53 \%)$, a branched prosthesis in $9(13 \%)$, and another tubular prosthesis in $23(34 \%)$. The supra-aortic vessels were re-implanted separately in $19(28 \%)$ or as island in 49 patients $(72 \%)$. Aortic valve repair was performed in 41 $(60 \%)$ and coronary artery bypass grafting in $13(19 \%)$. The period of cardioplegic cardiac arrest and cardiopulmonary bypass was $138 \pm 47$ minutes and $242 \pm 64$ minutes, respectively.

\section{Outcome}

The in-hospital mortality rate was $13 \%$ (9/68). Five patients died of cardiac failure. Of theses patients, cardiac malperfusion was documented in 3 and coronary artery stenosis in 2. In addition, the cause of death was visceral ischemia in 2, pulmonary failure in 1 , and stroke in 1 . The re-exploration rate for bleeding was $16 \%(11 / 68)$, and $37 \% \quad(25 / 68)$ underwent prolonged ventilation time longer than 72 hours. The incidence of new stroke was $10 \%$ ( 3 permanent and 4 regressive), and the incidence of paraparesis was $1 \%(1 / 68)$.

The follow-up was $100 \%$ (mean, $23 \pm 17$ months) and 6 deaths $(9 \%)$ occurred, 4 non- and 2 aortic related. Of the 2

TABLE 2. Size of E-vita open stent graft in acute aortic dissection $(\mathrm{n}=68)$

\begin{tabular}{lc}
\hline Graft size (mm) & Patients \\
\hline 24 & $22(32)$ \\
28 & $23(34)$ \\
30 & $10(15)$ \\
33 & $5(7)$ \\
36 & $7(10)$ \\
40 & $1(1)$ \\
\hline
\end{tabular}

Data in parentheses are percentages. 
aortic-related deaths, 1 occurred after 2 months of secondary visceral ischemia, verified by laparotomy, and 1 after secondary endovascular intervention and aortoesophageal fistula 2 years postoperatively. The actuarial survival rate, including in-hospital mortality, was $82 \%$ after 1 and $74 \%$ after 3 years (Figure 1). Seven (10\%) endovascular and one (1\%) surgical secondary intervention was performed in the downstream aorta, five at the first hospital stay and three during followup. The endovascular re-interventions took place in the distal aorta in 5 and in the distal aortic branches in 2 cases. One patient underwent replacement of the thoracoabdominal aorta because of aneurysm progression. The rate of freedom from secondary intervention in the downstream aorta after 1 and 4 years was $92 \%$ and $82 \%$, respectively (Figure 2). Of the 5 Marfan patients, to date, 1 required aortic endovascular reintervention without complications. In the others, the aorta remained stable over time.

The status of the whole aorta and the false lumen perfusion was evaluated by computed tomography in 59 patents postoperatively. Along the covered part of the descending aorta thrombus formation in the false lumen was observed in all patients postoperatively and was complete in $51(86 \%)$. Distal to the stent graft at the thoracoabdominal level, the rate of complete thrombosis was significantly less $(P<.01)$ (Table 3). A complete aortic and clinical status evaluation was available at a minimum follow-up of 6 months for 49 patients ( $3 \pm 2$ follow-up examinations/patient). The rate of complete false lumen thrombosis at the stent graft level increased up to $94 \%(46 / 49, \mathrm{P}=.84)$. At the thoracobdominal level, the rate of complete and partial thrombosis increased and the incidence of false lumen patency decreased to $18 \%$ $(9 / 49, P=.11)$. The clinical status was evaluated as normal in 36 patients $(73 \%)$ and 4 patients $(8 \%)$ required help for the daily activities. A total of 24 patients $(49 \%)$ returned to

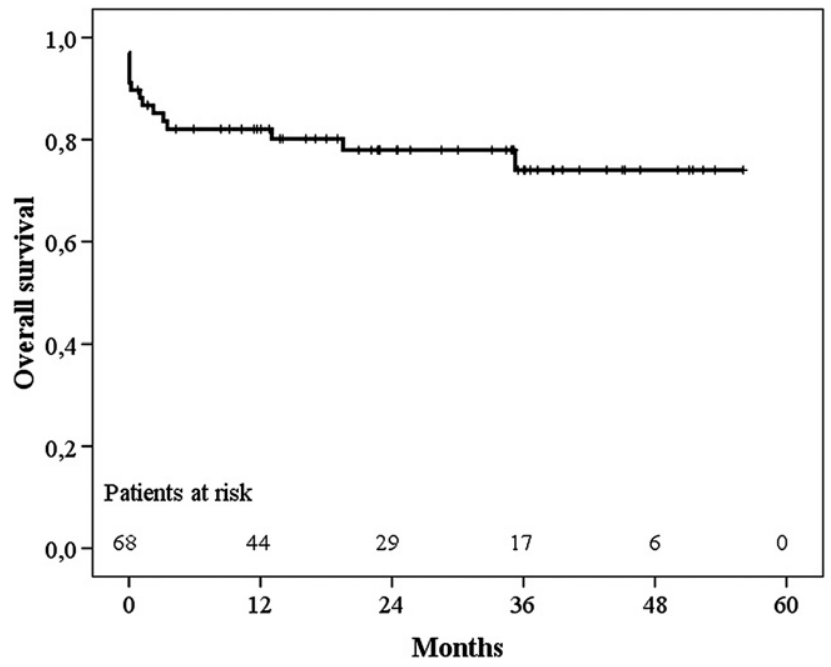

FIGURE 1. Actuarial survival by Kaplan-Meier method, including inhospital and follow-up mortality.

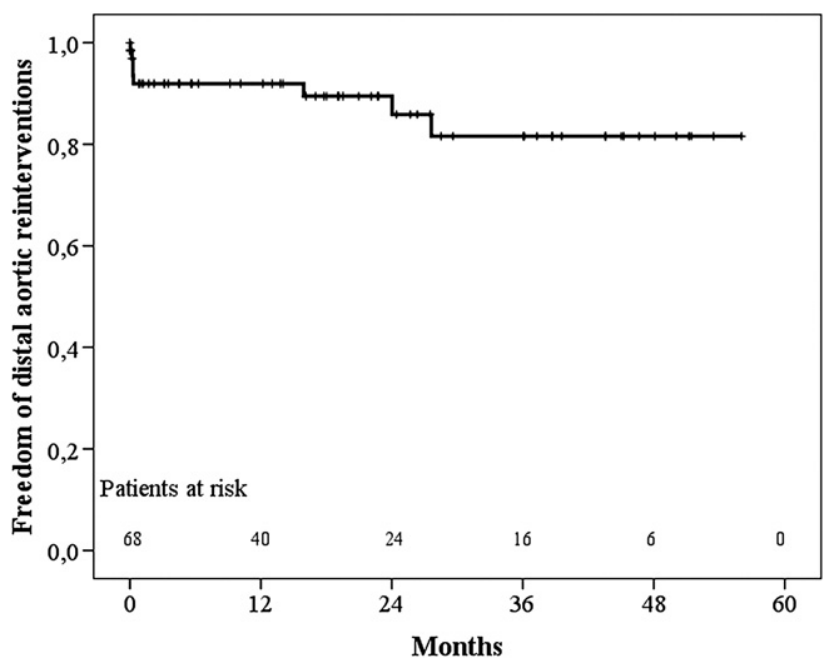

FIGURE 2. Freedom of secondary intervention in downstream aorta and aortic branches.

work, but they were younger than those staying home (mean age, $50 \pm 11$ versus $64 \pm 9$ years, $P<.01$ ).

\section{DISCUSSION}

In acute type A aortic dissection, emergency surgery of the proximal aorta represents the standard treatment to achieve improved patient survival. ${ }^{8}$ Resection of the primary intimal tear and repair of the aortic sinuses and valve represent well-established surgical principles, but the extension of aortic repair distally remains a matter of controversy. Arch replacement is sometimes required for resection of primary or additional tears, for securing the distal anastomosis by resection of fragile aortic tissue, and for reconstruction of the head vessels. The procedure can be performed safely using hypothermic circulatory arrest and selective cerebral perfusion; thus, aggressive arch replacement seems to be acceptable for select cases. ${ }^{9-12}$ The fate of the false lumen, which usually stays patent over time, correlates well to aortic enlargement, reoperation, and adverse outcome. ${ }^{13-17}$ The presumed rate of distal reoperation is $15 \%$ to $30 \%$ within 10 years; however, this

TABLE 3. Behavior of false lumen after antegrade stent grafting of descending aorta

\begin{tabular}{lcc}
\hline \multicolumn{1}{c}{ Variable } & $\begin{array}{c}\text { False lumen } \\
\text { postoperatively }(\mathbf{n}=\mathbf{5 9})\end{array}$ & $\begin{array}{c}\text { False lumen in } \\
\text { follow-up }(\mathbf{n}=\mathbf{4 9})\end{array}$ \\
\hline $\begin{array}{l}\text { Stent graft level } \\
\quad \text { Complete thrombosis }\end{array}$ & $51(86)$ & $46(94)$ \\
$\quad \begin{array}{l}\text { Partial thrombosis } \\
\text { Patent }\end{array}$ & $8(14)$ & $3(6)$ \\
Distal to stent graft & - & - \\
Complete thrombosis & $19(32)$ & $20(41)$ \\
Partial thrombosis & $17(29)$ & $20(41)$ \\
Patent & $23(39)$ & $9(18)$ \\
\hline
\end{tabular}

Data in parentheses are percentages. 
has probably been underestimated because most publications have used the Stanford classification and have not differentiated between extension of false lumen beyond the arch and extension solely in the proximal aorta, a distinction made under the DeBakey classification (type I and II), such that in the DeBakey type II, the process of dissection is interrupted after ascending aortic and/or hemiarch resection. Thus, simultaneous splinting of the true lumen to induce false lumen thrombosis is an attractive goal of this approach in DeBakey type I dissections. Of concern is the extension of a difficult and dangerous operation. However, the reported in-hospital mortality rate of $13 \%$, although not fully satisfactory, is similar to the results of sole proximal repair. The International Registry of Acute Aortic Dissection has reported a mortality rate of $15 \%$ to $30 \%$, depending on the clinical status of the patients at presentation, and similar results have been reported by others. ${ }^{24,25}$ Although not randomized, the International E-vita Open Registry data have demonstrated a cohort of $49 \%$ unstable patients before surgery, with $85 \%$ undergoing emergency surgery within 24 hours after onset of symptoms, explaining the mortality rate. The common cause of death was cardiac failure, which correlated to preoperative cardiac malperfusion or coronary artery disease.

Although the descending aorta cannot be inspected by the surgeon operating by way of a median sternotomy, stent graft placement in an antegrade fashion into the downstream aorta can be safely performed. Thus, additional entries can be excluded and stabilization of the true lumen can be achieved, splinting simultaneously the distal anastomosis between the descending aortic stump and the E-vita graft, because backflow by way of the false lumen is eliminated, while protamine is administered. The hybrid stent graft in place represents a safe landing zone for potential late aortic complications, which can easily be treated by thoracic endovascular aortic repair. This approach is well established in Japan using home-made grafts ${ }^{3,19}$; however, the excellent results could not reproduced in Europe using commercial stent grafts for the downstream aorta. ${ }^{20}$ Complications such as proximal endoleak, bare spring penetration of the arch, pseudoaneurysm formation, and migration of the grafts led to the development of the E-vita open hybrid prosthesis. The immediate thrombosis rate of the false lumen along the covered descending aorta was satisfactory ( $86 \%$ ), which increased to $94 \%$ during follow-up. However, the thrombosis rate distally increased to $41 \%$ over time with full-false lumen patency of only $18 \%$ during follow-up, although statistically not significant. Five endovascular and one surgical aortic reintervention demonstrated the importance of a close aortic imaging control. A secondary intervention can be performed safely using the stentgraft as an anchor. ${ }^{21}$ Previous studies demonstrated a tendency to progressive thrombus formation distal to stent graft and shrinkage of the false lumen ${ }^{22,23}$; thus, the probability of a need for a secondary endovascular intervention might be limited to cases of aneurysmal progression.

Of concern was the $10 \%$ rate of new temporary or permanent cerebral events. All participating centers favored moderate hypothermia combined with bilateral selective cerebral perfusion for brain protection. However, we demonstrated that the required time for stent graft placement and deployment does not increase the time of selective cerebral perfusion compared with total arch replacement, suggesting that the prevalence of stroke should be related to the results of sole arch replacement. ${ }^{4}$

The presented multicenter cooperation for the evaluation of antegrade stent grafting is unique but included considerable limitations, such as the lack of randomization and different operative protocols among the surgeons. However, the study results have confirmed the feasibility of a simultaneous proximal and distal aortic repair in acute dissection with results comparable with total arch replacement. Although long-term follow-up data are still to come, we propose the use of a hybrid stent graft in selected cases depending on the characteristics of the dissection. A spontaneous thrombosis of the false lumen after isolated proximal repair has been reported, with an incidence of about $20 \%$; thus, the indication for additional stent grafting should be adjusted to the extent of the dissection, the characteristics of the distal perfusion and the identification of re-entries. A thrombosis rate of the false lumen of more than $90 \%$ can be achieved at the stent graft level and probably $40 \%$ distally. However, the prerequisite for this should be an interdisciplinary approach of cardiac surgeons, cardiologists, and anesthetists, with a fast, hemodynamically controlled, accurate diagnosis of an acute aortic dissection, ideally located within a hybrid room, and offering the option of immediate treatment, either surgery and/or intervention.

\section{References}

1. Kato M, Ohnishi K, Kaneko M, Ueda T, Kishi D, Mizushima T, Matsuda H. New graft-implanting method for thoracic aortic aneurysm or dissection with a stented graft. Circulation. 1996;94:188-93.

2. Karck M, Chavan A, Hagl C, Friedrich H, Galanski M, Haverich A. The frozen elephant trunk technique: A new treatment for thoracic aortic aneurysms. J Thorac Cardiovasc Surg. 2003;125:1550-3.

3. Uchida N, Ishihara H, Shibamura H, Kyo Y, Ozawa M. Midterm results of extensive primary repair of the thoracic aorta by means of total arch replacement with open stent graft placement for an acute type A aortic dissection. J Thorac Cardiovasc Surg. 2006;131:862-7.

4. Jakob H, Tsagakis K, Tossios P, Massoudy P, Thielmann M, Buck T, Eggebrecht H, Kamler M. Combining classic surgery with descending sten grafting for acute DeBakey type I dissection. Ann Thorac Surg. 2008;86:95-101.

5. Dobrilovic N, Elefteriades JA. Stenting the descending aorta during repair of type A dissection: Technology looking for an application? J Thorac Cardiovasc Surg. 2006;131:777-8.

6. Tsagakis K, Pacini D, Di Bartolomeo R, Benedik J, Cerny S, Gorlitzer M, et al. Arch replacement and downstream stent grafting in complex aortic dissection: First results of an international registry. Eur J Cardiothorac Surg. 2010 June 1 [Epub ahead of print].

7. Jakob H, Tsagakis K, Leyh R, Buck T, Herold U. Development of an integrated stent graft-Dacron prosthesis for intended one-stage repair in complex thoracic aortic disease. Herz. 2005;30:766-8. 
8. Erbel R, Alfonso F, Boileau C, Dirsch O, Eber B, Haverich A, et al. Task Force on Aortic Dissection, European Society of Cardiology. Diagnosis and management of aortic dissection. Eur Heart J. 2001;22:1642-81.

9. Kazui T, Yamashita K, Washiyama N, Terada H, Bashar AH, Suzuki T, et al. Impact of an aggressive surgical approach on surgical outcome in type A aortic dissection. Ann Thorac Surg. 2002;74:1844-7.

10. Tan ME, Dossche KM, Morshuis WJ, Kelder JC, Waanders FG, Schepens MA. Is extended arch replacement for acute type A aortic dissection: An additional risk factor for mortality? Ann Thorac Surg. 2003;76:1209-14.

11. Hagl C, Ergin MA, Galla JD, Lansman SL, McCullough JN, Spielvogel D, Sfeir P, Bodian CA, Griepp RB. Neurologic outcome after ascending aortaaortic arch operations: Effect of brain protection technique in high-risk patients. J Thorac Cardiovasc Surg. 2001;121:1107-21.

12. Pacini D, Leone A, Di Marco L, Marsilli D, Sobaih F, Turci S, et al. Antegrade selective cerebral perfusion in thoracic aorta surgery: Safety of moderate hypothermia. Eur J Cardiothorac Surg. 2007;31:618-22.

13. Halstead JC, Meier M, Etz C, Spielvogel D, Bodian C, Wurm M, et al. The fate of the distal aorta after repair of acute type A aortic dissection. J Thorac Cardiovasc Surg. 2007;133:127-35.

14. Zierer A, Voeller RK, Hill KE, Kouchoukos NT, Damiano RJ Jr, Moon MR. Aortic enlargement and late reoperation after repair of acute type A aortic dissection. Ann Thorac Surg. 2007;84:479-86.

15. Geirsson A, Bavaria JE, Swarr D, Keane MG, Woo YJ, Szeto WY, Pochettino A. Fate of the residual distal and proximal aorta after acute type A dissection repair using a contemporary surgical reconstruction algorithm. Ann Thorac Surg. 2007; 84:1955-64.

16. Park KH, Lim C, Choi JH, Chung E, Choi SI, Chun EJ, et al. Midterm change of descending aortic false lumen after repair of acute type I dissection. Ann Thorac Surg. 2009;87:103-8.
17. Fattouch K, Sampognaro R, Navarra E, Caruso M, Pisano C, Coppola G, et al. Long-term results after repair of type A acute aortic dissection according to false lumen patency. Ann Thorac Surg. 2009;88:1244-50.

18. Borst HG, Walterbusch G, Schaps D. Extensive aortic replacement using "elephant trunk" prosthesis. Thorac Cardiovasc Surg. 1983;31:37-40.

19. Shimamura K, Kuratani T, Matsumiya G, Kato M, Shirakawa Y, Takano H, et al. Long-term results of the open stent-grafting technique for extended aortic arch disease. J Thorac Cardiovasc Surg. 2008;135:1261-9.

20. Herold U, Tsagakis K, Kamler M, Massoudy P, Assenmacher E, Eggebrecht H, et al. Change of paradigms in the surgical treatment of complex thoracic aortic disease. Herz. 2006;31:434-42.

21. Pichlmaier MA, Teebken OE, Khaladj N, Weidemann J, Galanski M, Haverich A. Distal aortic surgery following arch replacement with a frozen elephant trunk. Eur J Cardiothorac Surg. 2008;34:600-4.

22. Tsagakis K, Kamler M, Kuehl H, Kowalczyk W, Tossios P, Thielmann M, et al. Avoidance of proximal endoleak using a hybrid stent graft in arch replacement and descending aorta stenting. Ann Thorac Surg. 2009;88:773-9.

23. Gorlitzer M, Weiss G, Meinhart J, Waldenberger F, Thalmann M, Folkmann S, et al. Fate of the false lumen after combined surgical and endovascular repair treating Stanford type A aortic dissections. Ann Thorac Surg. 2010;89:794-9.

24. Rampoldi V, Trimarchi S, Eagle KA, Nienaber CA, Oh JK, Bossone E, et al., International Registry of Acute Aortic Dissection (IRAD) Investigators. Simple risk models to predict surgical mortality in acute type A aortic dissection: The International Registry of Acute Aortic Dissection score. Ann Thorac Surg. 2007;83:55-61.

25. Geirsson A, Szeto WY, Pochettino A, McGarvey ML, Keane MG, Woo YJ, et al. Significance of malperfusion syndromes prior to contemporary surgical repair for acute type A dissection: Outcomes and need for additional revascularizations. Eur J Cardiothorac Surg. 2007;32:255-62. 